\title{
The Relationship Between International Diversification and Business Performance of Chinese Commercial Banks
}

\author{
Tingting $W u^{1}$, Yanbin $W u^{2}$ \\ ${ }^{1}$ School of Finance, Shanghai University of International Business and Economics, Shanghai, China \\ ${ }^{2}$ School of Law, Fudan University, Shanghai, China
}

Email address:

ttw@suibe.edu.cn (Tingting Wu),wuyb16@fudan.edu.cn (Yanbin Wu)

\section{To cite this article:}

Tingting Wu, Yanbin Wu. The Relationship Between International Diversification and Business Performance of Chinese Commercial Banks. Journal of Finance and Accounting. Vol. 5, No. 3, 2017, pp. 87-95. doi: 10.11648/j.jfa.20170503.11

Received: January 20, 2017; Accepted: April 17, 2017; Published: May 4, 2017

\begin{abstract}
Chinese banking industry speeds up the process of internationalization as the global economy integrates and Chinese government accelerates the going out strategy. Many Chinese commercial banks explore overseas market by setting up new branches or merge and acquisition. Under the background, this paper uses empirical study to analyze the relationship between the degree of banks' internationalization and business performance. Firstly, principal component analysis is applied to measure the degree of banks' internationalization. Then, the paper constructs two models to analyze the panel data of five state-owned commercial banks, the second one with financial crisis as dummy variable. The results indicate that there is a U-shape relationship between the degree of banks' internationalization and business performance in the first model without dummy variable. In the second model adding dummy variable, the financial crisis not only deteriorates Chinese commercial banks' performance, but also makes the relationship between degree of internationalization and business performance become negative in 2008 while the degree of internationalization has positive influence on operational performance in years except for 2008.
\end{abstract}

Keywords: The Degree of Internationalization, Business Performance, Financial Crisis

\section{Introduction}

The financial system in China is dominated by indirect financing, so Chinese banking industry occupies an important position in the whole financial system. Therefore, the performance of banking system can make significant influence on capital operation performance of the whole society. With the economic globalization, many large-scale commercial banks which have completed shareholding reform speed up their internationalization. The international development of commercials banks not only offers service for many Chinese enterprises which go global or invest abroad, but also explores new market and enhances competitiveness in global banking industry.

The economic internationalization brings opportunities as well as risks and challenges. The 2008 global financial crisis triggered by subprime crisis had resulted in serious turbulence in the financial systems of many countries. There have been several classical studies on the relationship between international operation and business performance since the end of last century when globalization fostered. Especially after the 2008 financial crisis, an increased focus on this issue has spurred deeper and continuous research. This paper mainly pays attention to the measurement of Chinese banks' internationalization, the relationship between the degree of internationalization and banks' operation performance, and the impact of financial crisis on Chinese banking industry. After figuring out these issues, Chinese large-scale commercial banks can better evaluate their present degree of internationalization and plan the direction for future development. In addition, it will also offer references for the global development of other smaller Chinese banks when they are making international strategy.

Compared with small and medium banks, the beginning of state-owned commercial banks' internationalization is earlier and the policy support is stronger. In addition, the state-owned commercial banks have greater capacity for expanding international market than small and medium banks and the related data are easier to collect. Therefore, this paper mainly 
studies on the relationship between degree of internationalization and business performance of the five biggest state-owned banks: Bank of China (BOC), Industrial and Commercial Bank of China (ICBC), Bank of Communications (BOCOM), China Construction Bank (CCB) and Agricultural Bank of China (ABC).

This paper is going to firstly conduct the literature review to learn the previous studies of the relationship between the degree of internationalization and business performance. Then the measurement of degree of internationalization is concluded by the principal components analysis. After that, the paper constructs two models to analyze the panel data, the second one with financial crisis as dummy variable. At last, several conclusions and suggestions are made based on the empirical study results.

\section{Literature Review}

There is constant argument about the relationship between international operation and business performance. The results of plenty of empirical studies differ from industry to industry, which include positive relationship, negative relationship, $U$ shape, inverted U shape and S-shape curve etc. Some even conclude that there is no relationship between them.

Errunza and Senbet [1] (1984) made research on the sample of security market data and found that better market assessment is along with higher degree of internationalization. Michel and Shaked [2] (1986) studied on 58 American multinational companies and 43 non-U.S. multinational companies by regarding the shareholders' return as performance indicator. The analysis showed that shareholders' return in domestic companies were higher than that in international companies, which indicated corporation internationalization was negatively related with business performance. Collins [3] (1990) separated research target into three sample group: domestic enterprises, enterprises investing in developed countries and enterprises investing in developing countries. The degree of multinationality was measured by the ratio of overseas sales to total sales and the performance was measured by financial risk. The result indicated that there was no performance difference between enterprises investing in developed countries and domestic enterprises, but the performance of enterprises investing in developing countries was poor. Capar and Kotabe [4] (2003) proved that there was U-shaped curvilinear relationship between internationalization and performance in service firms by testing sample of 81 major German service firms which spanned across four industries. The findings showed that as the degree of internationalization increased, the performance level would decline. But they were positively related when the degree of internationalization exceeded certain level. Ruigrok, Amann and Wagner [5] (2007) investigated 87 Swiss multinational companies in manufacturing industries over an 8-year period, which suggested that there was S-shaped relationship between internationalization and performance. Junyun [6] (2011) found that there was a U-shape relationship between the degree of internationalization and business performance from a resource perspective based on the sample of representatives of Chinese public enterprises in 2007. In the background of developing countries such as China, the degree of internationalization had scale effect and scope effect, so it must reach certain degree to enhance the business performance. Ting and Delian [8] (2012) used some listed manufacturing companies in 2008 as research sample and the empirical study results showed that the degree of internationalization had weak positive influence on operational performance of manufacturing companies but it was not statistically significant. Dong and Jianhan [11] (2016) used sample data on private sector nationwide obtained by the CPC Central Committee United Front Work Department, investigating the relationship between the internationalization strategy of private enterprises, heterogeneous of investor and firm performance. They found out that internationalization strategy played a significant positive role in promoting firm performance through empirical study.

In previous studies, the relationship between internationalization and performance has been mostly tested based on the sample of manufacturing industries and most studies on bank internationalization were from the theoretical perspective. Based on the particularity and professionalism of banking industry, this paper selects Chinese commercial banks as the sample to study on the relationship between internationalization and performance and applies principal component analysis to obtain more precise measure of the degree of bank internationalization. These would be the possible innovations of this paper.

\section{Measurement of Banks' Internationalization Degree}

The first purpose of this paper is to find a measurement of the degree of banks' internationalization (DOI). In order to quantify the degree of banks' internationalization, numeric data from 2007 to 2014 are collected from the five banks' annual reports: the ratio of overseas assets to total assets (X1), the ratio of overseas profits to total profits (X2), the ratio of overseas operating income to total operating income (X3) and the ratio of overseas employment to total employment (X4). The data of BOCOM's overseas employment were not disclosed in annual reports until 2010, so there are only three variables $(\mathrm{X} 1, \mathrm{X} 2, \mathrm{X} 3)$ of the bank. It is true that many other factors can also represent the degree of banks' internationalization such as overseas merger and acquisition or overseas financial services, but it is hard to quantify them and some data are not disclosed publicly. That is the reason why only the above four variables are chosen for further empirical study.

This paper uses principal component analysis to quantify the degree of banks' internationalization and get the DOI index based on the results of factor scores. The analysis is used separately for the five banks so the structure of each bank's DOI index is different as well.

Based on the analysis results, total factor scores are 
calculated to evaluate the degree of commercial banks' internationalization (DOI). There is output of single factor score in SPSS. The following is the formula to calculate the total factor scores.

$$
\begin{gathered}
\text { DOI of } \mathrm{BOC}=57.195 \% \times \mathrm{F}_{1}+28.871 \% \times \mathrm{F}_{2} . \\
\text { DOI of } \mathrm{ICBC}=92.045 \% \times \mathrm{F}_{1} . \\
\text { DOI of } \mathrm{BOCOM}=76.148 \% \times \mathrm{F}_{1} . \\
\text { DOI of CCB }=46.438 \% \times \mathrm{F}_{1}+27.054 \% \times \mathrm{F}_{2} . \\
\text { DOI of } \mathrm{ABC}=91.420 \% \times \mathrm{F}_{1} .
\end{gathered}
$$

Table 1. DOI Index for the Five Banks.

\begin{tabular}{llllll}
\hline Year & BOC & ICBC & BOCOM & CCB & ABC \\
\hline 2007 & 1.3745 & -1.0615 & 0.2411 & 0.0058 & -0.5964 \\
2008 & -0.3858 & -0.8373 & -1.3678 & -0.2234 & -1.1001 \\
2009 & 0.4161 & -0.5306 & 0.0262 & -0.0216 & -0.5870 \\
2010 & 0.1499 & -0.2923 & -0.3658 & 0.4295 & -0.4184 \\
2011 & -0.2469 & -0.1787 & -0.2487 & -0.9174 & -0.3357 \\
2012 & -0.4270 & 0.2742 & 0.0583 & -0.2734 & 0.5774 \\
2013 & -0.5056 & 1.0130 & 0.3001 & 0.0701 & 0.8476 \\
2014 & -0.3751 & 1.6132 & 1.3566 & 0.9304 & 1.6126 \\
\hline
\end{tabular}

Data Source: Calculation Based on SPSS Output.

\section{Empirical Study on Panel Data}

\subsection{Variables Selection}

The panel data of the five biggest state-owned banks (BOC, $\mathrm{ICBC}, \mathrm{BOCOM}, \mathrm{CCB}$ and $\mathrm{ABC}$ ) have been collected to conduct the empirical study. The dependent variable is return on assets (ROA), the kernel variable is degree of internationalization (DOI) and the control variables are divided into internal factors and external factors. All the data are collected from banks' annual report and CEInet Statistic Database.

Dependent Variable ROA.Usually the profitability indicator is used to evaluate business performance, of which ROA (return on assets) and ROE (return on equity) are widely chosen. ROA shows how well a company uses assets to generate earnings and ROE measures a firm's efficiency at generating profits from every unit of shareholders' equity. In commercial banks, the percentage of bank's own capital to assets is quite low for the reason that most funds come from clients' deposit. Therefore, the indicator ROA reflects banks' capital operation ability more comprehensively, which is thus chosen as the dependent variable to measure banks' performance.

Kernel Variable DOI. The degree of commercial banks' internationalization is measured by the DOI index calculated in previous part. From the perspective of profession and advantages of banking services, commercial banks can realize expansion and reduce total cost through transnational operation. Thus the expected relationship between DOI and banks' performance is positive.

Non-Performance Loan Ratio (NPL). The NPL ratio is the ratio of the amount of nonperforming loans to the total amount of outstanding loans the bank holds, which measures the quality of a bank's asset.

Loan Loss Provision Coverage Ratio (LLPCR). It is an indicator of how protected a bank is against future losses. A higher ratio means the bank has the ability to withstand future risks better, including unexpected losses beyond the loan loss provision.

Cost-Income Ratio (CIR). The ratio distinctly shows how efficiently the company is operated. Lower cost and higher income means the bank is more profitable, which strengthen the bank's competitiveness at the same time.

Capital Adequacy Ratio (CAR). It is expressed as a percentage of a bank's risk weighted credit exposures, which represents a bank's capacity to meet the liabilities and other risks such as credit risk, operational risk etc.

Total Assets $(\log (\mathrm{TA}))$. It gives a clear view of the commercial banks' market influence and market shares. This paper takes the logarithm of total assets for better analysis. There are different conclusions about the relationship of total assets and ROA in literature. Some hold the view that the development of Chinese banking industry has economy of scale. Some think the expansion of assets is along with the reduction of management efficiency.

Gross Domestic Product (log (GDP)). It is a measure of macroeconomic activities. The commercial banks play a main role in public fund operation, which would be affected seriously by the macroeconomic trends.

Total Market Value of Listed Shares (log (TMV)). It gives a clear view of the development of Chinese stock market. Stock market is the main channels for direct financing. There is a substitutable relationship between banking services and stock market. The direct and indirect financing can replace each other under the condition when the total fund demand keeps constant. Therefore, the expected relationship between TMV and ROA is negative.

Broad Money $(\log (\mathrm{M} 2))$. It shows the monetary policy of central bank. The business performance of commercial banks would be influenced by the policy choices since they are the main channels for monetary policy transmission.

Dummy Variable. In order to study on whether there is a significant difference of banks' performance between financial crisis and general economic environment, this paper uses dummy variable(DUM) as an independent variable: $\mathrm{DUM}=1$ when year $=2008$; DUM $=0$ when year $\neq 2008$. The 2008 subprime mortgage crisis was a global financial disaster, thus this paper expects that the financial crisis has negative impact on business performance of Chinese commercial banks.

In general, time-series data related with price should be adjusted because the influence of inflation needs to be excluded for more accurate analyzing results. Both fixed base price index and chain price index can be used for adjustment. This paper chooses CPI (Consumer Price Index) as fixed base price index to adjust the collected time-series data which include total assets of commercial banks and the three external factors: GDP, total market value of listed shares and M2. The base year is 2004 . 


\subsection{Model Set-Up}

This paper will conduct two regressions in the following. The first model will make regression analysis to all the variables except for dummy variable, mainly in order to evaluate the relationship between degree of internationalization and business performance of commercial banks. The second model will add dummy variable on the basis of the first model, focusing on the influence of 2008 financial crisis on performance of commercial banks and the relationship between degree of internationalization and business performance of commercial banks.

\subsubsection{Basic Model}

The adopted regression model is as follows:

$$
\begin{aligned}
& \mathrm{ROA}_{\mathrm{it}}=\alpha_{\mathrm{i}}+\beta_{1} \mathrm{DOI}_{\mathrm{it}}+\beta_{2} \mathrm{LOG}(\mathrm{TA})_{\mathrm{it}}+\beta_{3} \mathrm{NPL}_{\mathrm{it}}+\beta_{4} \mathrm{LLPCR}_{\mathrm{it}}+\beta_{5} \mathrm{CIR}_{\mathrm{it}}+\beta_{6} \mathrm{CAR}_{\mathrm{it}}+\beta_{7} \mathrm{LOG}(\mathrm{GDP})_{\mathrm{t}}+\beta_{8} \mathrm{LOG}(\mathrm{M} 2)_{\mathrm{t}}+ \\
& \beta_{9} \mathrm{LOG}(\mathrm{TMV})_{\mathrm{t}}+\varepsilon_{\mathrm{it}}
\end{aligned}
$$

\subsubsection{Model with Dummy Variable}

The second model introduces the financial crisis as dummy variable into the basic model. The dummy variable is treated as kernel explanatory variable and the other variables in basic model are control variables. The model is constructed as follows:

$$
\begin{array}{r}
\mathrm{ROA}_{\mathrm{it}}=\alpha_{\mathrm{i}}+\beta_{1} \mathrm{DOI}_{\mathrm{it}}+\beta_{2} \mathrm{DUM}+\beta_{3} \mathrm{DUM} \mathrm{DOI}_{\mathrm{it}}+\beta_{4} \mathrm{LOG}(\mathrm{TA})_{i_{\mathrm{it}}}+\beta_{5} \mathrm{NPL}_{\mathrm{it}}+\beta_{6} \mathrm{LLPCR}_{\mathrm{it}}+\beta_{7} \mathrm{CIR}_{\mathrm{it}}+\beta_{8} \mathrm{CAR}_{\mathrm{it}}+\beta_{9} \mathrm{LOG}(\mathrm{GDP})_{\mathrm{t}}+ \\
\beta_{10} \mathrm{LOG}(\mathrm{M} 2)_{\mathrm{t}}+\beta_{11} \mathrm{LOG}(\mathrm{TMV})_{\mathrm{t}}+\varepsilon_{\mathrm{it}}
\end{array}
$$

\subsection{Unit Root Test}

In statistics, a unit root test tests whether a time series variable is non-stationary. If the time series is non-stationary, the regression of original series may result in spurious regression. Thus it is important to test the stationarity of time series before regression. There are mainly four methods of unit root test: LLC test, IPS test, Fisher-ADF test and
Fisher-PP test. These four tests all use the existence of a unit root which means the time series is non-stationary as the null hypothesis. Each method has its own advantages and disadvantages. In order to guarantee the robustness of analysis results, this paper uses the four methods to test unit root at the same time. The unit root test results exported by EViews 7 are as shown in Table 2.

Table 2. Unit Root Test Results of Variables.

\begin{tabular}{lllllll}
\hline Variables & Integration & Test Type & LLC test & IPS test & Fisher-ADF test & Fisher-PP test \\
\hline \multirow{2}{*}{ ROA (\%) } & \multirow{2}{*}{ I(1) } & Statistic & -7.8263 & -2.6281 & 27.0012 & 30.6318 \\
& & Probability & 0.0000 & 0.0043 & 0.0026 & 0.0007 \\
DOI & Statistic & -12.7918 & -4.7050 & 39.2663 & 45.9934 \\
& & Probability & 0.0000 & 0.0000 & 0.0000 & 0.0000 \\
LOG (TA) & $\mathrm{I}(0)$ & Statistic & -10.5044 & -6.3056 & 49.6160 & 60.8819 \\
& & Probability & 0.0000 & 0.0000 & 0.0000 & 0.0000 \\
NPL(\%) & I(0) & Statistic & -24.8574 & -13.3334 & 45.5214 & 43.5565 \\
& & Probability & 0.0000 & 0.0000 & 0.0000 & 0.0000 \\
LLPCR (\%) & I(0) & Statistic & -6.4593 & -1.5065 & 19.4033 & 8.5776 \\
& & Probability & 0.0000 & 0.0660 & 0.0354 & 0.0726 \\
CIR(\%) & I(1) & Statistic & -16.3427 & -8.1753 & 60.0520 & 74.1981 \\
& & Probability & 0.0000 & 0.0000 & 0.0000 & 0.0000 \\
CAR(\%) & $\mathrm{I}(1)$ & Statistic & -5.2789 & -1.7003 & 20.8463 & 23.0796 \\
& & Probability & 0.0000 & 0.0445 & 0.0222 & 0.0105 \\
LOG (GDP) & $\mathrm{I}(0)$ & Statistic & -6.1995 & -1.2607 & 16.8111 & 42.2245 \\
& & Probability & 0.0000 & 0.0937 & 0.0786 & 0.0000 \\
LOG (M2) & $\mathrm{I}(0)$ & Statistic & -20.5938 & -6.7947 & 55.3478 & 37.6301 \\
& & Probability & 0.0000 & 0.0000 & 0.0000 & 0.0000 \\
LOG (TMV) & $\mathrm{I}(0)$ & Statistic & -9.8958 & -4.8321 & 43.8806 & 52.8057 \\
\hline
\end{tabular}

Data Source: Output of EViews 7.

It can be easily concluded from Table 2 that under the confidence level of $90 \%$, there are six variable series (TA, NPL, LLPCR, GDP, M2 and TMV) are stationary because the test results reject the null hypothesis. The four series (ROA, DOI, CIR and CAR) are stationary after first order difference transformation.

\subsection{Panel Cointegration Test}

Cointegration means that there exists a long term relationship between two or more non-stationary time series. 
The model established on the variables is meaningful only when there is cointegrated combination of the series.

For the purpose of testing whether there exists a long term relationship between ROA of commercial banks and the independent variables, cointegration test is conducted. There are mainly three approaches of cointegration test, including Johansen test, Pedroni test and Kao test. This paper uses Kao test $^{1}$, of which the null hypothesis is that there is no cointegration relationship in panel data. The EViews test result is as followed:

Table 3. Cointegration Test.

\begin{tabular}{lll}
\hline & t-Statistic & Prob. \\
\hline ADF & -7.012915 & 0.0000 \\
Residual variance & 0.002476 & \\
HAC variance & 0.001826 & \\
\hline
\end{tabular}

Data Source: Output of EViews 7.

Table 3 gives a clear view that the null hypothesis should be rejected under the significance level of $5 \%$ since the probability is less than 0.5 . That is to say that there exists a long term relationship between the explained variable ROA and the explanatory variables.

\subsection{The First Model Without Dummy Variable}

First of all, F test and Hausman test are conducted to decide which kind of regression model is appropriate for the original data.

\subsubsection{F Test}

The null hypothesis of $F$ test is that the intercepts of different individual are the same, which means the true model is pooled regression model. The alternative hypothesis is that the intercept of different individual is different. The Eviews output shows the P-value is 0.0000 which is less than 0.5 . Thus the null hypothesis is rejected under the significance level of 5\%. The pooled regression model is not appropriate for the data in this paper.

\subsubsection{Hausman Test}

Hausman test is usually used to differentiate between fixed effects model and random effects model in panel data. In this case, the null hypothesis is random effects model while the alternative hypothesis is fixed effects model. The P-value is 0.0000 , thus the null hypothesis should be rejected under the significance level of 5\%.

Synthesizing the results of $\mathrm{F}$ test and Hausman test, this paper can make conclusion that the fixed effects model should be chosen to analyze the relationship between degree of internationalization and business performance of commercial banks.

\subsubsection{Regression Result}

The most common problems in adopting panel data model are the heteroscedasticity of cross section data and the autocorrelation of time series data, which can lead to

1 Kao test is appropriate for multiple variables in this situation. meaningless OLS result. In order to reduce the negative effect, this paper uses the estimation method of cross-section weights. After several adjustment and deletion of non-significant variables, the final regression result is shown below.

Table 4. The Regression Result.

\begin{tabular}{lllll}
\hline Variable & Coefficient & Std. Error & t-Statistic & Prob. \\
\hline C & 1.9674 & 0.3841 & 5.1216 & 0.0000 \\
DOI?^2 $^{\wedge}$ & 0.0253 & 0.0118 & 2.1388 & 0.0407 \\
NPL? & 0.0069 & 0.0021 & 3.1740 & 0.0035 \\
LLPCR? & 0.0012 & 0.0001 & 10.5116 & 0.0000 \\
CAR? & 0.0326 & 0.0098 & 3.3318 & 0.0023 \\
LOG(TMV?) & -0.0875 & 0.0241 & -3.6278 & 0.0010 \\
Fixed Effects (Cross) & & & & \\
BOC--C & -0.0278 & & & \\
ICBC--C & 0.0914 & & & \\
BOCOM--C & -0.0629 & & & \\
CCB--C & 0.1535 & & & \\
ABC--C & -0.1542 & & & \\
Weighted Statistics & & & & \\
R-squared & 0.9633 & Adjusted R-squared & 0.9524 \\
F-statistic & 87.6311 & Prob(F-statistic) & 0.0000 \\
\hline
\end{tabular}

Data Source: Output of EViews 7.

The regression equation based on the regression result can be written as:

\subsubsection{Result Analysis}

From the perspective of statistical test, the regression result is satisfactory. First of all, t test shows that all the coefficients of the six independent variables are statistically significant under the significance level of 5\% since their $\mathrm{p}$ values are all smaller than 0.05. Secondly, the prob(F- statistic $)=0.0000<$ 0.05 , which means the overall estimated multiple regression is statistically significant. Last but not the least, the adjusted $\mathrm{R}^{2}$ in the regression model is 0.9524 , which indicates that the estimated regression line is well fitted because $95.24 \%$ of the total variance in ROA can be explained by the regression model.

The main purpose of this paper is to study on relationship between the degree of banks' internationalization and business performance. The coefficient of $\mathrm{DOI}^{2}$ is 0.0253 that means it is a U-shape relationship between the degree of internationalization and ROA. There exists an inflection point. When DOI is less than the inflection point, ROA decreases as the DOI grows. When DOI is more than the inflection point, ROA increases as the DOI increases. In initial stage of transnational expansion, Chinese commercial banks would encounter lots of difficulties. Before they figure out solutions to the problems, the banks' internationalization would affect their operational performance negatively. There still exist lots of problems in the process of Chinese commercial banks' transnational operation.

Firstly, the distribution of overseas branch is uneven, most concentrating on Asia such as Hong Kong, Macao, Singapore etc. Although Chinese banks have set up about 880 branches in mature economic entity or international financial center, there are 735 in Hong Kong accounting for $83.52 \%$ in total 
amount. Only 75 branches are established in developed countries in Europe or America. This situation may result from the expansion strategy of Chinese banks that firstly occupy Asian-Pacific region where the culture, language and customs are similar to China to establish business relationship. However the European Union and North American countries are also China's important economic and trade partners with frequent business and large amount of transaction volume. The branches of Chinese banks can not satisfy the financial demand occurred in the trade, which leads to the reducing of commercial banks' operating income.

$$
\begin{gathered}
\text { BOC: } \mathrm{ROA}=-0.0278+1.9674+0.0253 \times \mathrm{DOI}^{2}+0.0069 \times \mathrm{NPL}+0.0012 \times \mathrm{LLPCR}+0.0326 \times \\
\text { CAR }-0.0875 \times \mathrm{LOG}(\mathrm{TMV})
\end{gathered}
$$

$$
\begin{gathered}
\mathrm{ICBC}: \mathrm{ROA}=0.0914+1.9674+0.0253 \times \mathrm{DOI}^{2}+0.0069 \times \mathrm{NPL}+0.0012 \times \mathrm{LLPCR}+0.0326 \times \\
\mathrm{CAR}-0.0875 \times \mathrm{LOG}(\mathrm{TMV})
\end{gathered}
$$

$$
\begin{gathered}
\text { BOCOM: } \mathrm{ROA}=-0.0629+1.9674+0.0253 \times \mathrm{DOI}^{2}+0.0069 \times \mathrm{NPL}+0.0012 \times \mathrm{LLPCR}+ \\
0.0326 \times \mathrm{CAR}-0.0875 \times \mathrm{LOG}(\mathrm{TMV})
\end{gathered}
$$

$$
\begin{gathered}
\mathrm{CCB}: \mathrm{ROA}=0.1535+1.9674+0.0253 \times \mathrm{DOI}^{2}+0.0069 \times \mathrm{NPL}+0.0012 \times \mathrm{LLPCR}+0.0326 \times \\
\mathrm{CAR}-0.0875 \times \mathrm{LOG}(\mathrm{TMV})
\end{gathered}
$$

$$
\begin{gathered}
\mathrm{ABC}: \mathrm{ROA}=-0.1542+1.9674+0.0253 \times \mathrm{DOI}^{2}+0.0069 \times \mathrm{NPL}+0.0012 \times \mathrm{LLPCR}+0.0326 \times \\
\mathrm{CAR}-0.0875 \times \mathrm{LOG}(\mathrm{TMV})
\end{gathered}
$$

Secondly, the banking business is lack of diversification. In 2014, the data from British magazine The Banker showed that the net interest income of Chinese four state-owned commercial banks ranked top five in the world from the perspective of business type of operating income, but American large international banks occupied obvious advantages in intermediate business income such as fees and commission. The profits of Chinese banks still rely mostly on traditional interest margin. The intermediate service is an important indicator to measure the degree of banks' internationalization which is widely valued by banking industry in mature economies. In transnational operation, Chinese commercial banks mainly offer traditional services for Chinese corporations and individuals and are less engaged in developing new clients and meeting their special needs in host countries. This will blunt the competitive advantages and restrain the profit growth compared with other international commercial banks.

Last but not the least, Chinese commercial banks are still short of compound talents. The competition in banks' internationalization is ultimately the competition of talents. On the one hand, the internationalization experience of Chinese banks is insufficient. Qualified talents who are experienced and familiar with international rules are required to guarantee relative advantages in the competition with foreign banks in global market. On the other hand, the human resource recruitment and management of Chinese banks would be regulated by the related law in host countries; and it is difficult to hire international talents skilled both in international rules and domestic practices. Domestic employees dispatched by parent banks know little in international rules and local culture, leading to hinder localized operation and globalization layout formation.

In this situation, Chinese commercial banks begin to take innovated measures to adapt to the global financial environment.
They learn from large international banks, explore new internal management and operation mechanism and conduct merge and restructuring to enhance their business performance. After Chinese commercial banks survive in this adaptation period, they would move to the next stage when their profit ability strengthens and the performance grows.

Variables CIR, $\log (\mathrm{TA}), \log (\mathrm{GDP})$ and $\log (\mathrm{M} 2)$ are deleted because they are not statistically significant. From the view of economic significance, it indicates that the cost income ratio, assets scale, the GDP and the monetary policy have relatively little influence on the business performance of Chinese commercial banks.

The actual relationship between ROA and loan loss provision coverage ratio, capital adequacy ratio and total market value of listed shares are the same as expected. The reason has been discussed in the section of variables selection. The non-performance loan ratio has positive influence on ROA which is the opposite of the expectation. Poorer asset quality of commercial banks is along with good business performance, which indicates the unhealthy development of Chinese commercial banks to certain degree.

\subsection{The Second Model with Dummy Variable}

The second regression adds the dummy variable (DUM) representing the impact of financial crisis to the regression model. $\mathrm{F}$ test and Hausman test are also conducted first. Taking both results of $\mathrm{F}$ test and Hausman test into account, this paper chooses the fixed effects model to analyze the relationship between degree of internationalization and business performance of commercial banks.

\subsubsection{Regression Result}

The dummy variable is added into the regression model by method of addition and multiplication at the same time. The regression result is shown in Table 5 . 
Table 5. The Regression Result with Dummy Variable.

\begin{tabular}{lllll}
\hline Variable & Coefficient & Std. Error & t-Statistic & Prob. \\
\hline C & 3.3973 & 1.5491 & 2.1931 & 0.0374 \\
DOI? & 0.0287 & 0.0137 & 2.0878 & 0.0468 \\
DUM? & -0.2666 & 0.0846 & -3.1511 & 0.0041 \\
DOI?*DUM? & -0.2260 & 0.0548 & -4.1225 & 0.0003 \\
LOG(TA?) & -0.4467 & 0.1331 & -3.3551 & 0.0024 \\
LLPCR? & 0.0007 & 0.0002 & 3.1997 & 0.0036 \\
CIR? & -0.0094 & 0.0031 & -3.0041 & 0.0058 \\
CAR? & 0.0250 & 0.0087 & 2.8860 & 0.0077 \\
LOG(M2?) & 0.3981 & 0.1265 & 3.1457 & 0.0041 \\
LOG(TMV?) & -0.1427 & 0.0667 & -2.1382 & 0.0421 \\
Fixed Effects (Cross) & & & & \\
BOC--C & -0.0004 & & & \\
\hline
\end{tabular}

\begin{tabular}{|c|c|c|c|}
\hline Variable & Coefficient & Std. Error & Prob. \\
\hline ICBC--C & 0.2418 & & \\
\hline BOCOM--C & -0.4869 & & \\
\hline CCB--C & 0.3120 & & \\
\hline $\mathrm{ABC}--\mathrm{C}$ & -0.0666 & & \\
\hline \multicolumn{4}{|c|}{ Weighted Statistics } \\
\hline R-squared & 0.9703 & Adjusted R-squared & 0.9554 \\
\hline F-statistic & 65.2583 & Prob(F-statistic) & 0.0000 \\
\hline
\end{tabular}

Data Source: Output of EViews 7.

The regression equation based on the regression result can be written as:

$$
\begin{array}{r}
\text { BOC: } \mathrm{ROA}=-0.0004+3.3973+0.0287 \times \mathrm{DOI}-0.2666 \times \mathrm{DUM}-0.2260 \times \mathrm{DOI} \times \mathrm{DUM}-0.4467 \times \\
\mathrm{LOG}(\mathrm{TA})+0.0007 \times \mathrm{LLPCR}-0.0094 \times \mathrm{CIR}+0.0250 \times \mathrm{CAR}+0.3981 \times \mathrm{LOG}(\mathrm{M} 2)-0.1427 \times \mathrm{LOG}(\mathrm{TMV}) \\
\mathrm{ICBC}: \mathrm{ROA}=0.2418+3.3973+0.0287 \times \mathrm{DOI}-0.2666 \times \mathrm{DUM}-0.2260 \times \mathrm{DOI} \times \mathrm{DUM}-0.4467 \\
\times \mathrm{LOG}(\mathrm{TA})+0.0007 \times \mathrm{LLPCR}-0.0094 \times \mathrm{CIR}+0.0250 \times \mathrm{CAR}+0.3981 \times \mathrm{LOG}(\mathrm{M} 2)-0.1427 \times \mathrm{LOG}(\mathrm{TMV}) \\
\mathrm{BOCOM}: \mathrm{ROA}=-0.4869+3.3973+0.0287 \times \mathrm{DOI}-0.2666 \times \mathrm{DUM}-0.2260 \times \mathrm{DOI} \times \mathrm{DUM}- \\
0.4467 \times \mathrm{LOG}(\mathrm{TA})+0.0007 \times \mathrm{LLPCR}-0.0094 \times \mathrm{CIR}+0.0250 \times \mathrm{CAR}+0.3981 \times \mathrm{LOG}(\mathrm{M} 2)-0.1427 \times \mathrm{LOG}(\mathrm{TMV}) \\
\mathrm{CCB}: \mathrm{ROA}=0.3120+3.3973+0.0287 \times \mathrm{DOI}-0.2666 \times \mathrm{DUM}-0.2260 \times \mathrm{DOI} \times \mathrm{DUM}-0.4467 \times \\
\mathrm{LOG}(\mathrm{TA})+0.0007 \times \mathrm{LLPCR}-0.0094 \times \mathrm{CIR}+0.0250 \times \mathrm{CAR}+0.3981 \times \mathrm{LOG}(\mathrm{M} 2)-0.1427 \times \mathrm{LOG}(\mathrm{TMV}) \\
\mathrm{ABC}: \mathrm{ROA}=-0.0666+3.3973+0.0287 \times \mathrm{DOI}-0.2666 \times \mathrm{DUM}-0.2260 \times \mathrm{DOI} \times \mathrm{DUM}-0.4467 \times \\
\mathrm{LOG}(\mathrm{TA})+0.0007 \times \mathrm{LLPCR}-0.0094 \times \mathrm{CIR}+0.0250 \times \mathrm{CAR}+0.3981 \times \mathrm{LOG}(\mathrm{M} 2)-0.1427 \times \mathrm{LOG}(\mathrm{TMV})
\end{array}
$$

\subsubsection{Result Analysis}

In terms of statistical test, the coefficients of the seven independent variables are statistically significant under the significance level of $5 \%$. The overall estimated multiple regression is also statistically significant.

The degree of banks' internationalization has positive influence on business performance which is the same as the expectation after adding dummy variable representing financial crisis. Every unit increase in the degree of banks' internationalization will lead to that the average value of ROA increases by 0.0287 . The impact of financial crisis on commercial banks' operational performance is negative. In 2008 , the return on assets decreases by $0.2666 \%$ compared with that in other years holding other variables constant because of the financial disaster. The coefficient of DOI*DUM is -0.2260 while the coefficient of DOI is only 0.0287 , which means the degree of internationalization has negative influence on ROA in 2008. The empirical study results are reasonable. Although the developed countries suffered from the financial crisis most, the higher degree of internationalization of Chinese commercial banks makes them more integrated in the global financial market and thus their business performance becomes poorer.

The negative influence of financial crisis on Chinese commercial banks can mainly be identified in the following three aspects. Firstly, the declining performance or bankruptcy of foreign commercial banks leaded to the overseas investment loss of Chinese banks. Most Chinese banks expanded global market by holding shares, merging or setting up new branches. The loss included the direct investment on fixed income products such as sub-prime debt and Lehman bonds, and equity investment loss resulting from the stocks plunge. Secondly, the impact of financial crisis on real economy resulted in declining exports and hence the non-performing assets of Chinese banks increased. Exports always contribute a lot to Chinese economy growth and America is the largest export market for a long time. After 2008, the slowdown of American consumption leaded to that many Chinese enterprises had difficulty in continuous operation and the ability to pay out loans weakened. Therefore, many banks' loans to these companies become bad and doubtful debts. Thirdly, the global financial environment became worse and the world entered into a rate cut cycle. The profit of Chinese banks largely depends on the interest margin, thus the reduction of interest would make the scale of banks interest income decline a lot.

\section{Suggestions}

Global financial landscape and international regulation have undergone complex and profound changes after the financial crisis in 2008, which provides unprecedented opportunities for transnational operation of Chinese commercial banks.

Firstly, it could be seen that many American and European 
commercial banks suffered a lot in the financial crisis, especially some large international banks. It is well known that these banks created many derivatives and structured products with high leverage ratio, so they became insolvent after the financial system collapsed. In this background, some international banks began to sell overseas assets for enhancing liquidity and saving themselves. If Chinese commercial banks can fill the vacancy timely, they can expand more overseas market channels and acquire abundant business resources. Secondly, the financial demands of corporations in host countries increased. Some banks suffered a lot in the crisis so they were unable and unwilling to lend, which had to transfer credit assets. The clients in host countries began to seek financial services from Chinese banks, which offered opportunities for Chinese commercial banks to strengthen the business connection with enterprises in host country and develop high quality customers. Thirdly, the financial crisis also offered opportunities of talents recruitment. There were more 170 thousand layoffs in global financial industries in 2008. Actually this provides talents guarantee for Chinese banks to operate in foreign countries. The lack of compound talents is one important factor restraining the overseas development of Chinese commercial banks. Talents with experience play an essential role in the sustainable development of transnational operation.

There still exist several problems in the process of Chinese commercial banks' internationalization. At the same time, the macroeconomic environment such as financial crisis and RMB internationalization bring about lots of opportunities. Therefore, this paper offers some suggestions on the enhancement of Chinese commercial banks' internationalization.

\subsection{Emerging Market Exploration}

Chinese commercial banks should explore mature market and emerging market concurrently. After the 2008 financial crisis, the overall strength of emerging markets has been increasing and their potentials are shown. As Latin America, Africa and West Asia become important regions of China's foreign trade and investment, Chinese commercial banks should also target on them for overseas expansion. In addition, Chinese banks need pay attention to the opportunities to enhance the penetration in mature markets such as Europe and America.

\subsection{Business Localization}

Chinese commercial banks should be devoted to localization operation. As foreign corporations in host countries, Chinese banks need to deal with disadvantages of law, brand, resources and culture. Thus differentiation development is required based on each market and different functional planning. For example, in Middle East and Africa area, localized financial services can be provided considering local religion and the needs of economic development.

\subsection{Risk Control}

Chinese commercial banks should effectively control the risks in internationalization operation. The comprehensive competitive strength of Chinese banks is still far behind the large international banks. And the market risk, operation risk, law risk and credit risk are all complex problems in the face of Chinese banks' transnational development, which requires Chinese banks to place priority on controlling risks. After the financial crisis in 2008, the supervision legislation in many countries has changed a lot, so Chinese banks must know exactly about business-related regulations to avoid the compliance risks.

Recently, the Chinese government is pushing the establishment of Asian Infrastructure Investment Bank and the implementation of One Belt and One Road Strategy, which enhances the RMB internationalization and strengthens market basis of Chinese commercial banks' global development. In order to become the international first-class banks, Chinese commercial banks need to rationally determine and seize market growth and breakthrough points, speed up the transformation of business model and constantly enhance the core competitiveness and value creation ability on the basis of development of global economy.

\section{Conclusions}

The main purpose of this paper is to study on the relationship between the degree of Chinese commercial banks' internationalization and business performance. Although the expected relationship is positive, the actual empirical study shows more complex results. In the first model without dummy variable, there is a U-shape relationship between degree of banks' internationalization and business performance of Chinese commercial banks. In earlier stage, banks' operational performance becomes worse as the DOI increases. After the internationalization degree exceeds certain level, it has positive influence on the business performance. The second model with dummy variable indicates that financial crisis has negative impact on operational performance of Chinese commercial banks. The global financial disaster even results in that the degree of internationalization and business performance are negatively related in 2008 while they are positively related in other years except for 2008 .

\section{Acknowledgments}

This paper is financially supported by the National Social Science Foundation Project (16CGJ006) and the Shanghai Philosophy and Social Sciences Planning Project (2013BJB013).

\section{References}

[1] Errunza, VR \& Senbet, LW 1984, 'The effects of international operations on the market value of the firm: theory and evidence', The Journal of Finance, vol.36, pp.401-417. 
[2] Michel, A. \& Shaked, I 1986, 'Multinational corporations vs. domestic corporations: financial performance and characteristics', Journal of International Business Studies, vol.18, pp.89-100.

[3] Collins, JM 1990, 'A. market performance comparison of u. s. firms active in domestic developed and developing countries', Journal of International Business Studies, vol.21, pp.271-287.

[4] Capar, N. \& Kotabe, M. 2003, 'The relationship between international diversification and performance in service firms', Journal of International Business Studies, vol.34, pp.345-355.

[5] Ruigrok, W, Amann, W, \& Wagner, H. 2007, 'The internationalization- performance relationship at swiss firms: a test of the s-shape and extreme degrees of internationalization', Management International Review, vol.47, pp. 349-368.

[6] Junyun, Q. 2011, 'Research on relationship between degree of internationalization and enterprise performance in China from a resource perspective', Master paper, Beijing Jiaotong University.
[7] Meng, H, Jian, Q. \& Wendong, X. 2011, 'The internationalization of Chinese banks: status and strategy selection', The Banker, no.11, pp.67-69.

[8] Ting, L. \& Delian F. 2012, 'Empirical study on the relationship between internationalization and business performance of Chinese manufacturing companies', Journal of Yunnan Finance \& Economics University, vol.27, no.3, pp. 94-100.

[9] Lingyu, M. 2013, 'Empirical study on factors affecting Chinese commercial banks' business performance', Journal of Finance and Economics, no.02, pp.55-58.

[10] Haixi, J. \& Ying, J. 2014, 'Study on the internationalization development stages of China's state-owned commercial banks', Economic Perspectives, no.08, pp. 90-96.

[11] Dong, C. \& Jianhan, W. 2016, 'The internationalization strategy of private enterprises, heterogeneous of investors and firm performance', Journal of Shanxi University of Finance and Economics, vol.38, no.4, pp.74-86. 